\title{
A Novel Compensation Scheme Based on a Virtual Air Gap Variable Reactor for AC Voltage Control
}

\author{
J. Avila-Montes, Member, IEEE, David Campos-Gaona, Member, IEEE, E. Melgoza, Senior, IEEE \\ and J. R. Rodriguez-Rodriguez, Member, IEEE
}

\begin{abstract}
Voltage control based on reactive power compensation is a fundamental aspect of the operation of ac electric power systems. This paper presents a novel shunt compensation scheme based on a virtual air gap variable reactor. The scheme is fully developed, from the adaptation of the virtual air gap principle to high voltage applications and the determination of its expected performance, to the proposal of a digital cascade control using internal-model and proportionalintegral controllers. The suitability and flexibility of the device and the voltage control and reactive power compensation scheme are verified by means of laboratory tests performed in a smallscale prototype. Measured results show that the proposed device and its control provide a robust load compensation scheme for ac systems.
\end{abstract}

Index Terms - Air gap, Automatic voltage control, dc-dc power converters, electric variables control, magnetic variables control, PI control, reactive power control

\section{INTRODUCTION}

$\mathrm{T}$ WO important voltage regulation problems in EHV ac power systems with long transmission lines are the voltage drop at the receiving node in the case of high load, and an unacceptable voltage rise at the receiving node under light load conditions. Regarding the latter problem, currently fixed shunt reactors are the most common solution to limit this voltage variation. However by their characteristics of fixed susceptance, fixed reactors represent another load for the power system when the power supply and load conditions change, which affects the nodal voltage profile and loadability characteristics of the line [1]. Consequently, in order to improve the operation characteristics of power systems, variable shunt reactors are desirable [2]. Current technologies for variable reactors include tapped coils, adjustable air gaps,

\footnotetext{
${ }^{1}$ Manuscript received October 22, 2013. Accepted for publication March 11, 2014.

Copyright (c) 2014 IEEE. Personal use of this material is permitted. However, permission to use this material for any other purposes must be obtained from the IEEE by sending a request to pubs-permissions@ieee.org.

J. Avila-Montes is with Prolec General Electric, Applied Research Center. Apodaca 66629, México (e-mail:jesus.avilamontes@ge.com).

D. Campos-Gaona, E. Melgoza and J. R. Rodriguez-Rodriguez are with the Posgrado en Ingeniería Eléctrica, Instituto Tecnológico de Morelia, Morelia 58120, México (e-mail:davidcg@ieee.org; emv@ieee.org; jrrodriguezr@itmorelia.edu.mx)
}

saturation by de flux and thyristor control [3]-[4]. However, even though these technologies have proven useful for EHV regulation, there is still room for improvement in aspects like harmonic content, response time, continuous variation and control range.

In electrical networks where reactive power consumption and generation are reasonably predictable and stable, and a very fast response of the compensation scheme is not mandatory, the tapped coil variable shunt reactor (TCVR) as well as the adjustable air gap reactor (AAGR), are suitable solutions which have been successfully implemented. In these technologies, the inductance is varied by means of mechanical systems which change the number of electrical turns in the winding of the reactor [5], or adjust the air gaps of its magnetic circuit [6].

In EHV systems, a highly inductive load during the peak period can lead to a critical value in the voltage level, and consequently loss of stability of generator units previously operating close to stability limits. An event of this kind is more probable if uncontrolled shunt reactors or variable reactors with slow response are used for reactive power compensation. In order to endow variable reactors with a fast response, some design approaches have changed the mechanical inertia of actuators by the intrinsic time constant of an electromagnetic system. Thus, some technologies such as the dc flux saturated reactor (DCFSR) and the thyristor controlled variable reactor (TCR) have been implemented [7][9]. These technologies offer continuously adjustable inductance values, providing a fast and continuous reactive power control. However, wave distortion and harmonics have been reported as consequence of the saturation of the core in the case of DCFSR, or due to thyristor switching during TCR operation. Accordingly, new configurations and control methods have been developed in order to suppress the generation of harmonics, which can cause stability problems under some circumstances [10].

Besides the mentioned variable reactor technologies, a number of new approaches for variable reactors are being investigated [11]-[16]. These new technologies seek to improve some operating characteristics such as harmonic content, control circuit power/operating voltage, response time, range of regulation, smooth regulation of inductance and reactive power consumption, and applicability to EHV 
systems. These functionality requirements are being demanded by electrical utilities around the world for the solution of load compensation and voltage control problem in EHV systems.

This paper proposes a novel reactive power compensation scheme based on the virtual air gap reactor (VGR), a concept with the potential to fulfill the most desirable performance characteristics mentioned above, such as a wide range of regulation and low harmonic content. The paper is organized as follows: first, the operating principle of the virtual air gap reactor is reviewed, and some aspects of its design and operation characteristics for application on EHV systems are discussed. The construction of a small-scale prototype is described, followed by the consideration of the proposed control system, suitable for voltage regulation in conditions of variable load. Finally, experimental results are presented showing the performance of the combined variable reactor and voltage control scheme; the results demonstrate that the proposed device is a viable alternative for load compensation and voltage control in ac electrical systems.

\section{VGR CONCEPT}

\section{A. Virtual air gap}

The virtual air gap principle consists in the creation of zones with controlled saturation level, in a magnetic core, by an additional unidirectional magnetic flux, produced by pairs of auxiliary or control windings fed by an external controlled dc source. The controlled saturation zones are called virtual air gaps; they can be compared to conventional air gaps but their length depends on the magnitude of the current in the auxiliary windings [17]-[20], [26]. The auxiliary windings are embedded in the magnetic core, which is additionally magnetized by alternating current in the main winding. The main magnetic flux interacts with the flux produced by the auxiliary windings, resulting in a magnetic circuit with variable inductance.

Fig. 1 shows schematically the virtual air gap principle. The change of direction of the main magnetic flux through the virtual air gap zone, equivalent to the fringing which occurs in a real air gap, can be appreciated. If a single auxiliary winding is used to modify the local saturation level, it will create a dc flux around the whole magnetic circuit [18]. In order to avoid this effect, the virtual air gaps are created by pairs of auxiliary windings carrying currents with opposing polarity.

\section{B. Design aspects of VGR for EHV applications}

According to the virtual air gap principle, the VGR is equipped with three elemental components: one main winding, a magnetic core and a set of auxiliary (control) windings. The main winding is connected to the ac line, so the main magnetic flux is determined by the ac operating voltage of the VGR. The design of the main winding follows established practices applied to conventional high voltage fixed reactors. Thus, the main winding is typically made of continuous discs or interleaved discs, because of the requirements of high insulating capacity and a large number of turns. The core comprises one central column and two return legs to provide the closed magnetic path, through which the main flux is carried; at the same time, the central column provides the mechanical support for the main winding. The lateral legs also accommodate physical space to embed the set of auxiliary windings. The auxiliary windings require a big number of turns because of the high level of energy to be stored. On the other hand, the space to be occupied by the auxiliary windings should be reduced in order to minimize the cost and dimensions of the core. Therefore, a layer winding is the best choice for the auxiliary windings [21].

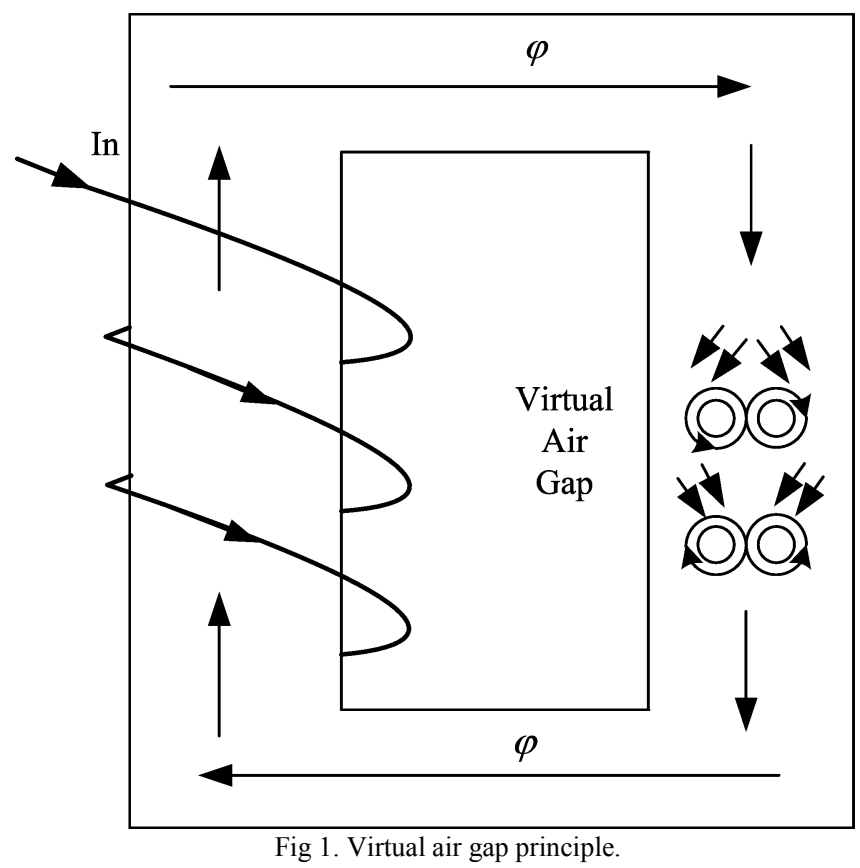

\section{Fundaments of VGR operation}

The electric and magnetic variables of the reactor, such as inductance, reactive power, magnetic flux density and main winding current, are interrelated, and the precise manner in which they interact has been investigated with the help of computational programs based on finite element analysis (FEA), a powerful tool that provides accurate and detailed computations of the magnetic field distribution in electrical machines [22]-[25].

Based on the conceptual design described in [21], [27], a $80 \mathrm{MVAR}$ VGR for operation at $500 \mathrm{kV}$ has been designed. A 2D nonlinear magnetostatic model of the designed VGR has been created in a finite element program, allowing the visualization of the impact of changes in the design parameters. As an illustration, Fig. 2 shows the distribution of magnetic flux in the core; the zones with magnetic flux distortion can be appreciated. It can be seen that the flux changes its direction on each magnetic distortion zone; thus, the virtual air gap flux pattern is equivalent to the flux pattern of physical air gaps.

The magnetization characteristic of the magnetic core with virtual air gaps, for different values of control current, has been calculated based on the 2D nonlinear FEA model. The results are shown in Fig.3. The flux linkage curves have been drawn as a function of the main winding current at constant 
control current. It can be seen that, when the control current is zero, the magnetization characteristic corresponds to the intrinsic magnetic core performance, but if the control current is raised, the flux linkage resembles a sigmoid curve, increasing abruptly when the main winding current reaches a critical value. This avalanche phenomenon is a consequence of the interaction between the magnetomotive forces of the main windings and the auxiliary windings [21].

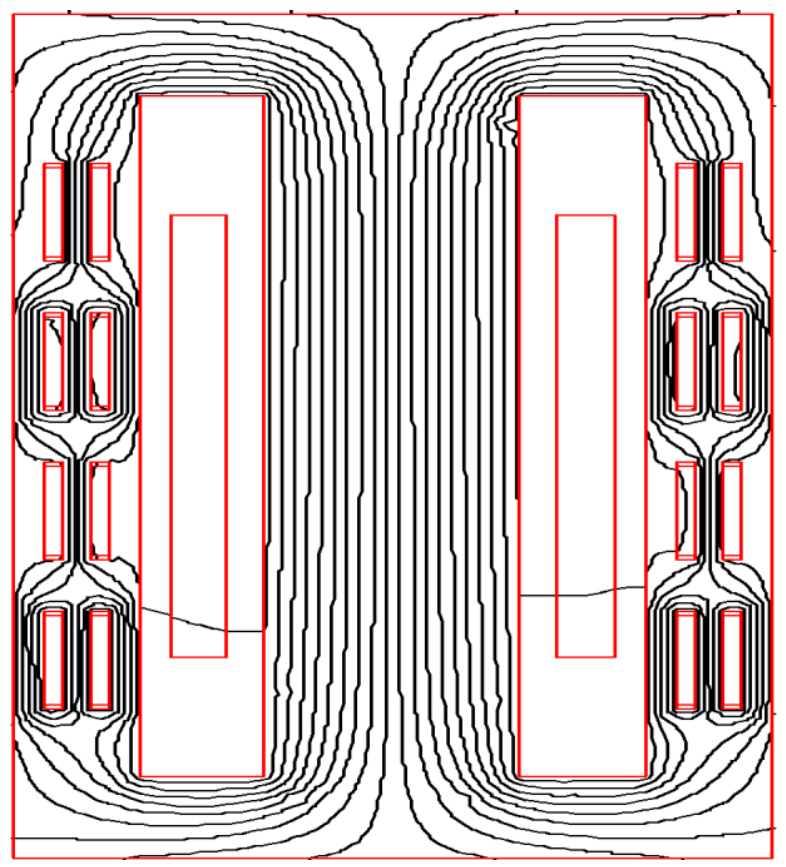

Fig 2. Computed flux plot for VGR design.

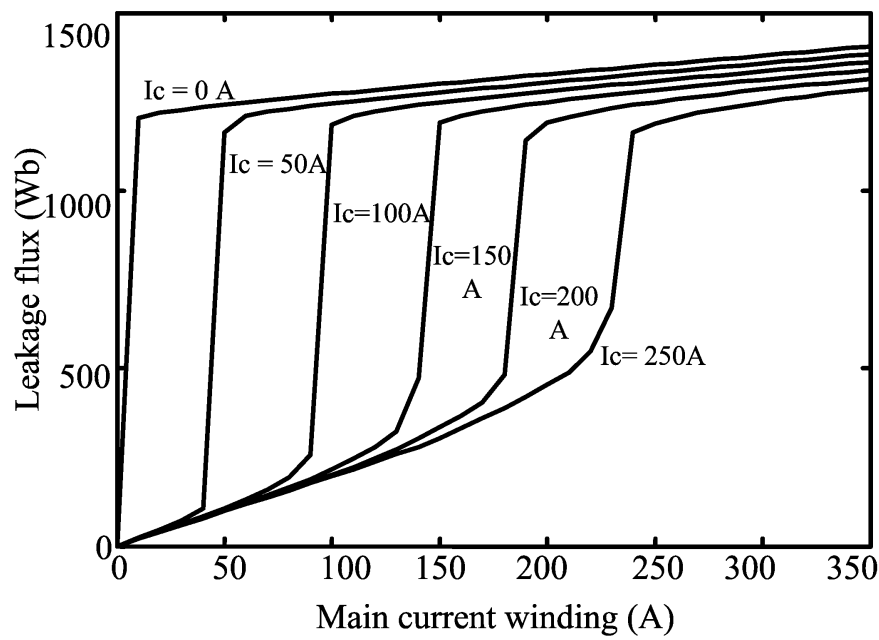

Fig 3. Computed magnetization curves as a function of the main current, for several control currents, for the proposed VGR design.

The interaction between main and dc magnetic flux changes the permeability of the core in the air gap zones. Accordingly, the magnetization characteristic of the complete magnetic circuit is modified. The result is an electromagnetic system with variable inductance. This is the most important feature of the magnetic response of the VGR, to be applied as part of a load compensation scheme.

Fig. 4 shows the inductance of the proposed VGR design, calculated from the magnetization characteristics, for the full range of control current; operation at rated ac voltage is assumed. The reactance as a function of the control current follows a similar inverse relation.

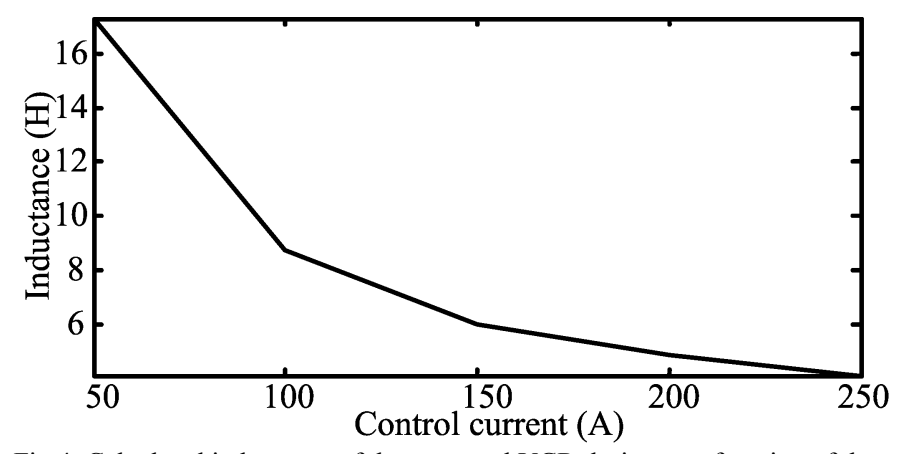

Fig 4. Calculated inductance of the proposed VGR design as a function of the control current.

The electric response of the VGR is defined by the reactive power consumption as a function of the control current. During operation as part of a compensation scheme, the VGR reactive power is adjusted depending on variations in the load connected to the power system, in order to keep a constant voltage. Fig. 5 shows the reactive power consumption for the simulated design, for the full range of control current.

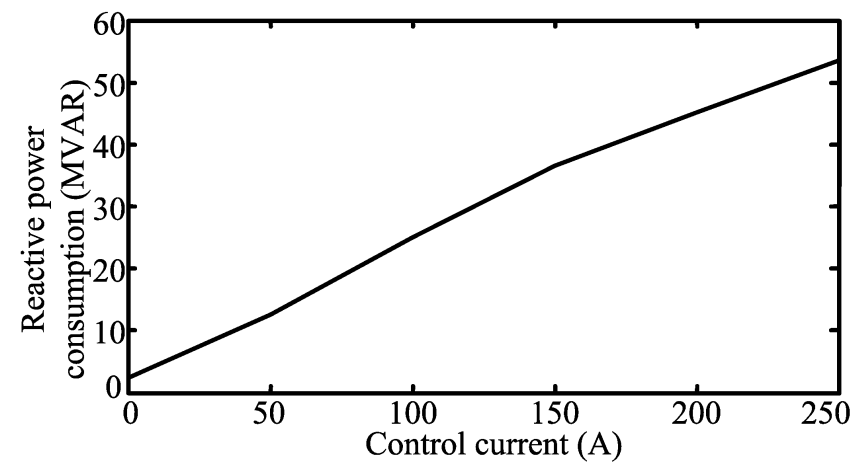

Fig 5. Calculated reactive power in the proposed VGR design as a function of control current.

\section{DESCRIPTION OF THE PROTOTYPE}

Based on the design concept described in [21], [27], a scaled prototype has been specified and manufactured, in order to test the performance of the compensation scheme. The proposed design concepts have been followed in detail as seen in Fig. 6. The main winding encircles the central column of the core, and auxiliary windings are embedded in two return legs. This last feature potentiates the proposed concept for power applications, because the control windings can be designed with enough turns to meet the requirements of energy storage. Otherwise, if auxiliary windings are placed in the top yoke, the VGR design cannot be manufactured following current practices for power transformers and shunt reactors [26]. 


\section{Description Of The CONTROL System}

\section{A. Operation of the Compensation Scheme}

The operation of the proposed compensation scheme consists in monitoring the nodal voltage at the load in order to detect any difference with respect to a reference value. When the load changes, the nodal voltage deviates from the reference value. As a result, a modulated control signal is obtained from the digital controller, leading to a corresponding magnitude of direct current supplied to the auxiliary windings, modifying the inductance value of the VGR, and consequently its reactive power consumption. The control system action is performed until the nodal voltage at the load reaches the reference value. Fig. 7 shows the scheme of the proposed solution.

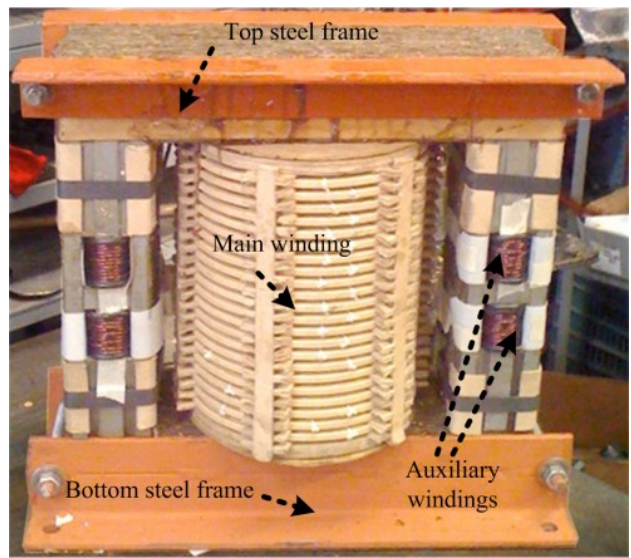

Fig. 6. VGR prototype.

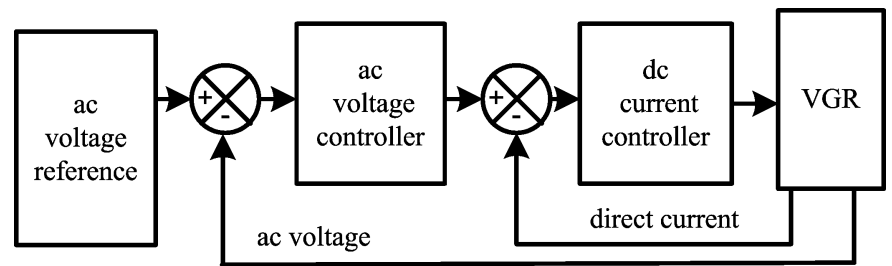

Fig. 7. Schematic diagram of the voltage control system.

\section{B. The Direct Current Controller}

The implementation of the direct current controller is based on the two-degrees-of-freedom internal model controller (IMC) [28]-[31]. The IMC approach is used due to its capabilities for performing robust control over the plant dynamics and because of the additional disturbance rejection provided by the second degree of freedom. These two characteristics are highly desirable for controlling the VGR given its plantparameter changing nature (i.e. the change of the control winding inductance with the magnitude of the magnetic flux) and the unavoidable disturbance produced by the functioning of the VGR which results in an unwanted induction of ac current in the control windings. Fig. 8 shows the two-degreesof-freedom IMC controller structure layout.

The "internal model" principle of the IMC states that the control over a plant can be performed if the control structure includes some representation of the process to be controlled. According to Fig. 8, the difference between the plant output $y(s)$ and the plant model output provides an estimation of the effect of the disturbance $d^{\prime}(s)$. Here $d^{\prime}(s)$ can be regarded as information that is missing in the model of the plant $P^{\prime}(s)$ inside of the controller and can be used to improve the control. The transfer function describing the dynamics of the control winding of the VGR is:

$$
P_{v g r}(s)=\frac{i_{d c}(s)}{u_{d c}(s)}=\frac{1}{L s+R}
$$

where $u_{d c}, i_{d c}, L$ and $R$ are the dc voltage, current, inductance and resistance of the control winding, respectively.

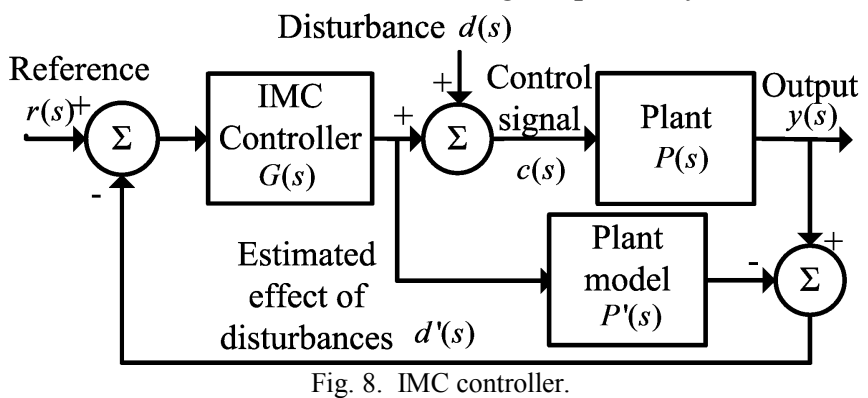

If the model of the control winding was an exact representation of the VGR itself and considering that no disturbance is present, the signal $d^{\prime}(s)$ would be zero and the closed loop system would then be equivalent to the open loop system. In this case an IMC controller of the type $P_{v g r}{ }^{r-1}(s)=L s+R$ would imply a perfect control. However, such a controller cannot be realized by several reasons, including the use of pure differentiators which cannot be implemented in practice. To solve the problem, the IMC control structure introduces a low pass filter $L(s)$ in cascade with the controller (i.e. $G(s)=L(s) P^{P^{-1}}(s)$ ) designed to make proper its transfer function by adding poles to $G(s)$. The filter, for a first order plant, is usually of the type $L(s)=\alpha /(s+\alpha)$ where $\alpha$ can be regarded as the bandwidth of the closed loop system. The use of $L(s)$ in the IMC controller structure could be regarded as a detriment of the controller performance; however, $\alpha$ can be set high enough to comply with the performance specifications for the plant, as long as the physical implementation of the controller allows it.

Fig. 9 shows the control structure of the VGR based on a "classic-type" IMC controller structure layout. The addition of an inner feedback loop with gain $G_{v g r}$ to the plant provides the additional degree of freedom of the IMC controller structure, and is useful to speed up the plant's load disturbance rejection by artificially moving the pole of the plant away from the origin in the complex plane [28], [30]. In this way, the transfer function of the plant augmented with the additional degree of freedom is:

$$
M(s)=\frac{P_{v g r}(s)}{1+P_{v g r}(s) G_{v g r}}=\frac{1}{P_{v g r}^{-1}(s)+G_{v g r}}=\frac{1}{L s+R+G_{v g r}}
$$


where the transfer function of the "classic-type" IMC controller of Fig. 9, after the addition of the inner control loop, takes the form:

$$
F(s)=\frac{G(s)}{1-G(s) M^{\prime}(s)}=\alpha L+\frac{\alpha\left(R+G_{v g r}\right)}{s}
$$

From (3), the proportionality constant $K_{P-v g r}$ and integral constant $K_{i-v g r}$ of the "classic-type" IMC controller can be calculated as $K_{P-v g r}=\alpha L$ and $K_{i-v g r}=\alpha\left(R+G_{v g r}\right)$

The additional degree of freedom is chosen here to make the controller dynamics and the load disturbance rejection as fast as the plant dynamics. This is achieved by moving the pole $G_{v g r}$ created by the inner feedback loop in $M(s)$, to match the pole of the IMC controller in the transfer function from the disturbance to output signal of Fig. 9, which is given by

$$
\frac{I_{d c}(s)}{d(s)}=\frac{M(s)}{1+F(s) M(s)}=\left(\frac{s}{s+\alpha}\right) \frac{1}{L s+R+G_{v g r}}
$$

It can be seen from this expression that the variables of the IMC controller structure are related to the model parameters, with the bandwidth $\alpha$ remaining as the only variable to be tuned. Since $\alpha$ controls the bandwidth of the closed loop system, it can be selected for a particular rise time, $t_{r}$, following the formula that relates the bandwidth with the rise time for a first degree under-damped system which is $\alpha \approx 2.2 / t_{r} \mathrm{rad}$.

If we set $G_{v g r}=\alpha L-R$, then the disturbances to the plant will have the same time constant as the IMC controller, that is:

$$
\frac{I_{d c}(s)}{d(s)}=\left(\frac{s}{s+\alpha}\right) \frac{1}{L s+R+\alpha L-R}=\frac{s}{L(s+\alpha)^{2}}
$$

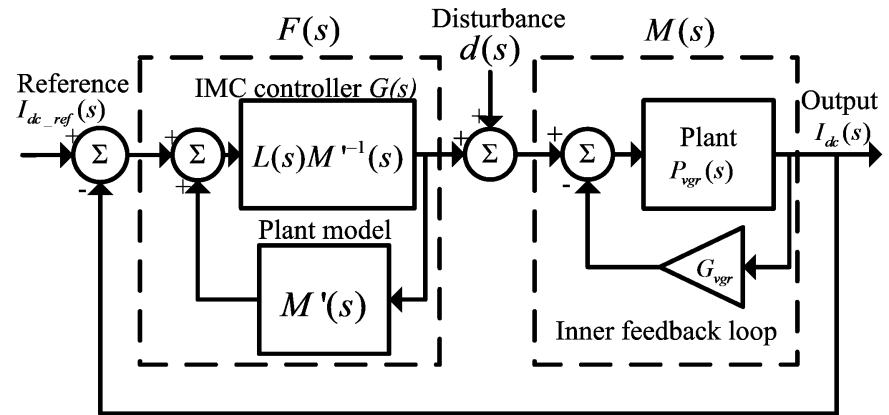

Fig. 9. DC current controller ("classic-type" two-degrees-of-freedom IMC controller).

In the experimental setup, $\alpha$ was selected for a direct current controller rise time of $20 \mathrm{~ms}$, which is within the speed response limits of the H-bridge converter.

\section{The AC Voltage Controller}

The numerical computation of the dynamics of the magnetic circuit of the VGR shows that the response time of the primary winding, in changing its inductance given a dc current in the control windings, varies in the range from $0.1 \mathrm{~ms}$ to $0.6 \mathrm{~ms}$ for a 1 to $12 \mathrm{~A}$ dc current range. Since these response times are much smaller than the specified response time of the ac voltage control loop (i.e. $200 \mathrm{~ms}$ ), it is assumed for simplicity that the change of the inductance is instantaneous and that the inductance is a linear function of the control current. For the VGR used in this experiment this function turns out to be

$$
L_{V G R}=-0.0606 I_{d c}+17.29
$$

As seen in (6) the VGR main winding inductance is assumed proportional to the control current, with an offset. Thus, a PI controller would reach zero steady state error. The proportional and integral constants $K_{p}$ and $K_{i}$ of the controller are selected to attain a $200 \mathrm{~ms}$ response time for the main winding inductance, which is enough for controlling the ac voltage level and connect in cascade with the direct current controller. Fig. 10 shows the ac voltage controller of the VGR.

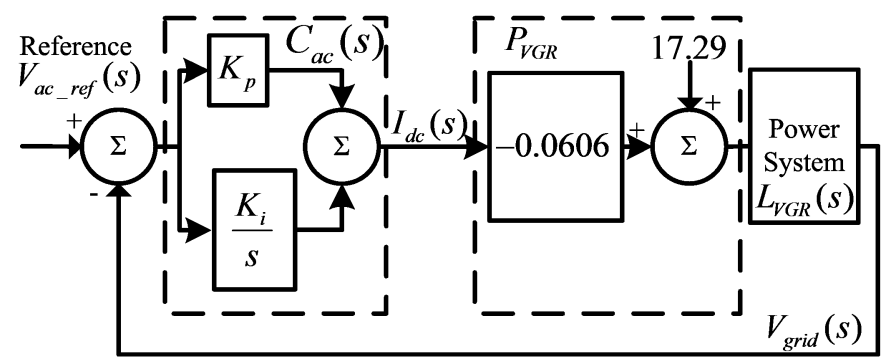

Fig. 10. AC voltage controller loop.

The ac voltage and the dc current controllers were implemented using the TMS320F28335 32-bit DSC (digital signal controller) from Texas Instruments, with a sampling time of $55.5 \mu \mathrm{s}$ ( 300 samples per $60 \mathrm{~Hz}$ cycle).

\section{H-BRIDGE CONVERTER}

The injection of the direct current to the control winding is made by a dc/dc converter based on the H-bridge topology, configured as a controlled current source as shown in Fig 11. The H-bridge structure is simple and easy to implement, and allows a precise voltage and current control with a response time only limited by its switching frequency [32], [33].

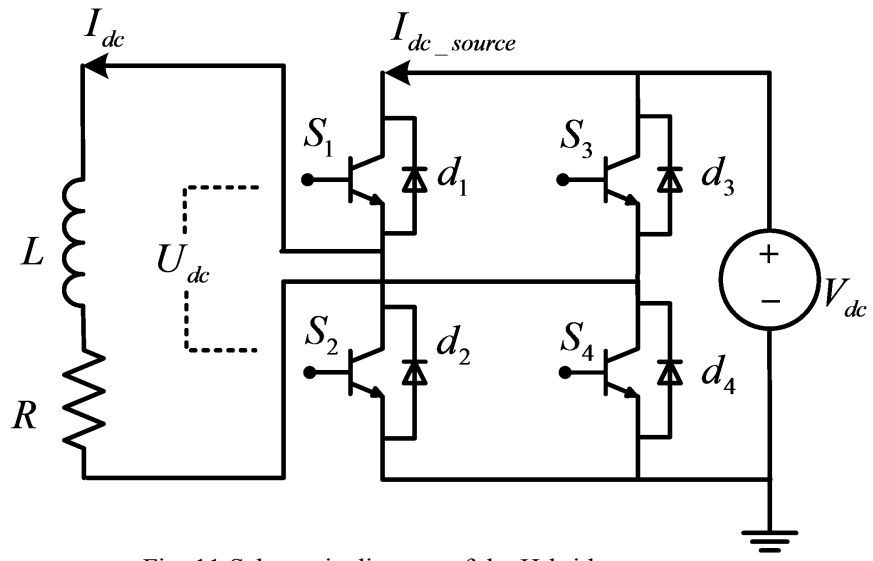

Fig. 11 Schematic diagram of the H-bridge converter. 


\section{EXPERIMENTAL SETUP}

\section{A. Power system representation}

In order to verify the performance of the proposed compensation scheme, several laboratory tests were conducted, with the following arrangement. The power system is represented as shown in Fig. 12.

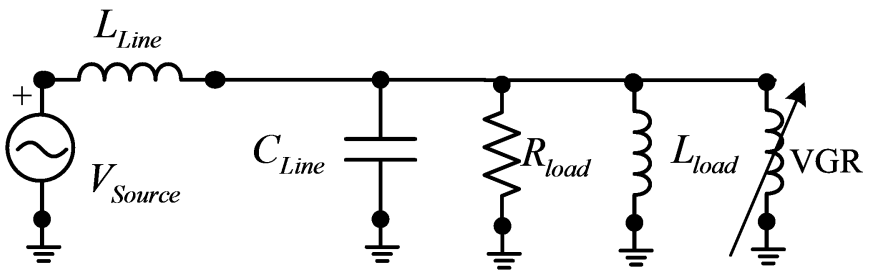

Fig. 12. Power system for laboratory tests.

The transmission line is represented by the inductor $L_{\text {Line }}$ and lumped capacitor $C_{\text {line }}$. The load ( $R_{\text {Load }}$ and $\left.L_{\text {Load }}\right)$ is connected in parallel with the VGR at the end of the line. This configuration is representative of real conditions in an ac power system.

\section{B. Description of the equipment installed in laboratory}

To perform the tests of the VGR performance, several components have been installed in the laboratory, such as resistive, inductive and capacitive load bridges to simulate the transmission line, the Ferranti phenomenon and the load connected at the receptor node.

The equipment installed in laboratory is shown in Fig. 13. Control system components are also included, such as a computer for DSC control and programming, a National Instruments USB-5261 data acquisition device (sampling frequency of $10 \mathrm{kHz}$ ), a $2 \mathrm{~kW}$ IGBT-based H-bridge, an ac voltage source and a dc voltage source.

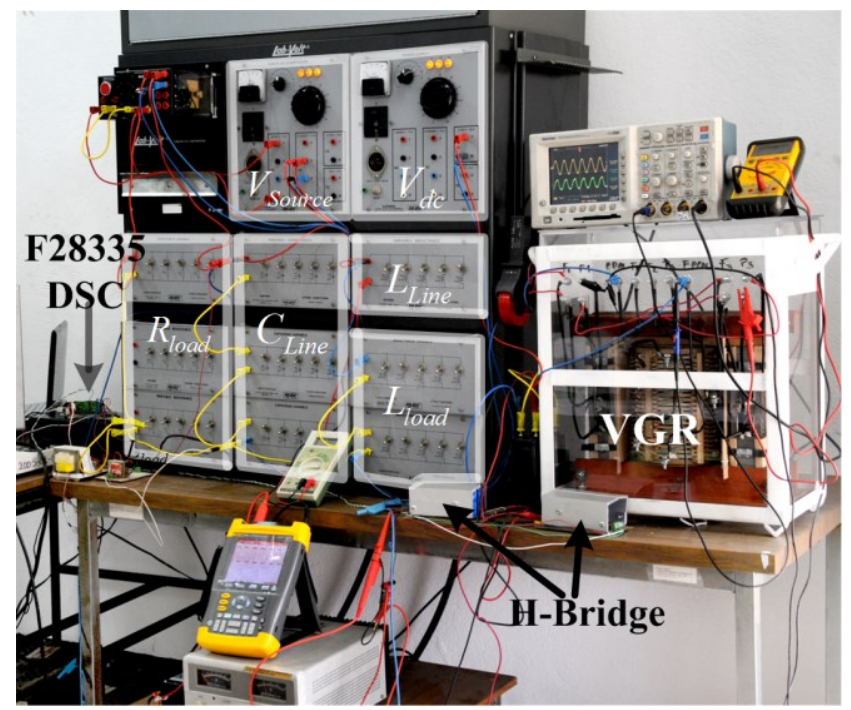

Fig. 13. Experimental test bench installed in laboratory.

\section{VGR PROTOTYPE EXPERIMENTAL RESULTS}

\section{A. Study cases}

The laboratory tests have been developed at low voltage (i.e. $100 \mathrm{Vrms}$ ), to comply with the ratings of installed equipment. The experiment parameters are shown in Table I. The test cases have been selected to fully verify the performance of the VGR and its control system.

TABLE I. EXPERIMENTAL STUDY CASES

\begin{tabular}{|c|c|c|}
\hline $\begin{array}{l}\text { Experimental } \\
\text { parameters }\end{array}$ & Load scenarios & Description \\
\hline \multirow{5}{*}{$\begin{array}{l}V_{\text {source }}=100 \mathrm{~V} \\
L_{\text {line }}=80 \mathrm{mH}\end{array}$} & $\begin{array}{l}R_{\text {load }}=120 \Omega \\
X_{L-\text { load }}=240 \Omega \\
X_{C-\text { line }}=723 \Omega\end{array}$ & $\begin{array}{l}\text { Initial condition. } \\
\text { The initial condition is } \\
\text { defined in order to } \\
\text { establish the nodal load } \\
\text { voltage at its nominal } \\
\text { value. }\end{array}$ \\
\hline & $\begin{array}{l}X_{L-\text { load }}=240 \Omega \\
X_{C-\text { line }}=723 \Omega\end{array}$ & $\begin{array}{l}\text { First load case } \\
\text { From the initial } \\
\text { condition, resistive load } \\
\text { has been disconnected. }\end{array}$ \\
\hline & $\begin{array}{l}R_{\text {load }}=80 \Omega \\
X_{L-\text { load }}=240 \Omega \\
X_{\text {C-line }}=150.33 \Omega\end{array}$ & $\begin{array}{l}\text { Second load case } \\
\text { Resistive load value } \\
\text { decreases with respect to } \\
\text { the initial condition. At } \\
\text { the same time, the shunt } \\
\text { capacitive reactance } \\
\text { increases. }\end{array}$ \\
\hline & $\begin{array}{l}R_{\text {load }}=80 \Omega \\
X_{L-\text { load }}=240 \Omega \\
X_{C-\text { line }}=109.16 \Omega\end{array}$ & $\begin{array}{l}\text { Third load case } \\
\text { From the second load } \\
\text { case, shunt capacitive } \\
\text { reactance has been } \\
\text { increased. }\end{array}$ \\
\hline & $\begin{array}{l}R_{\text {load }}=48 \Omega \\
X_{L-\text { load }}=240 \Omega \\
X_{C-\text { line }}=56.53 \Omega\end{array}$ & $\begin{array}{l}\text { Fourth load case } \\
\text { Resistive load value } \\
\text { decreases with respect to } \\
\text { the third load case. At } \\
\text { same time, the shunt } \\
\text { capacitive reactance } \\
\text { increases. }\end{array}$ \\
\hline
\end{tabular}

\section{B. Flexible shunt compensator steady state performance}

The steady state experimental results are presented in Fig. 14. It can be seen that the load voltage increases for all the tests when the control system is not engaged, but the voltage remains at nominal value when the control system is operating. This shows that the proposed compensation scheme is able to compensate all the tested load scenarios, managing to keep the nodal load voltage at its nominal value.

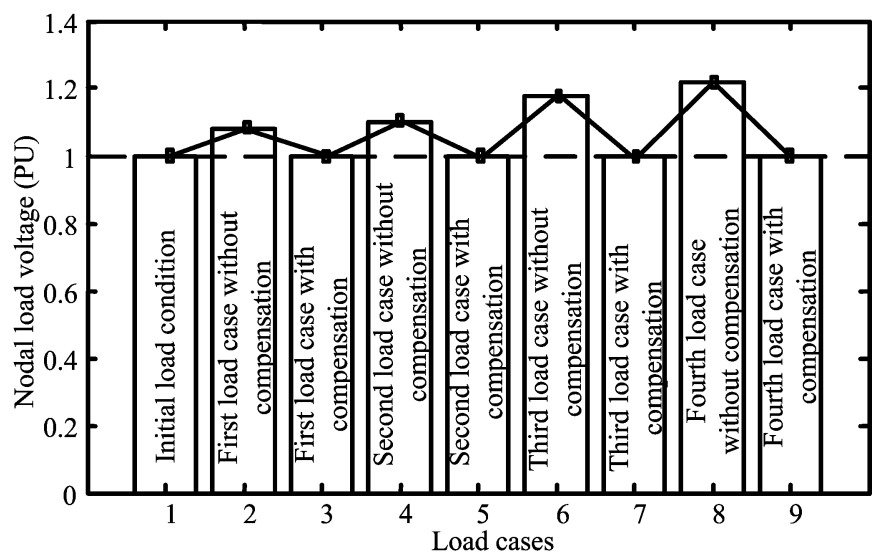

Fig. 14. Flexible shunt compensator steady state performance.

\section{Magnetic and electrical response of the VGR}

During the four different test cases proposed, the VGR prototype had to adjust its inductance and its corresponding reactive power consumption in order to keep the nodal load 
voltage at nominal value. For this, different control current values were supplied to the auxiliary windings, responding to the control system action. The variation of the VGR inductance and the reactive power consumption are shown in Figs. 15 and 16, respectively. These results validate the simulations developed for the proposed design, as discussed in Section II.

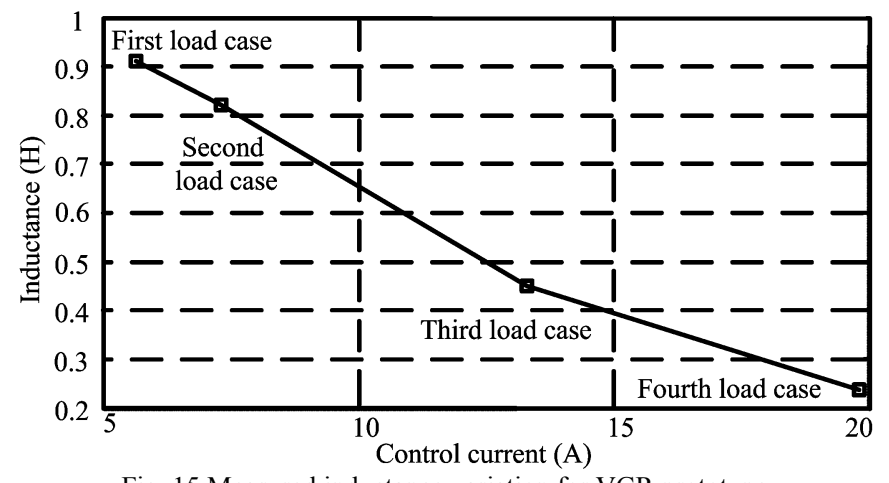

Fig. 15 Measured inductance variation for VGR prototype.

Fig. 16 shows that the reactive power consumption is adjusted in a range of 84.2 VARS during the complete experiment, in order to keep a constant voltage at the load.

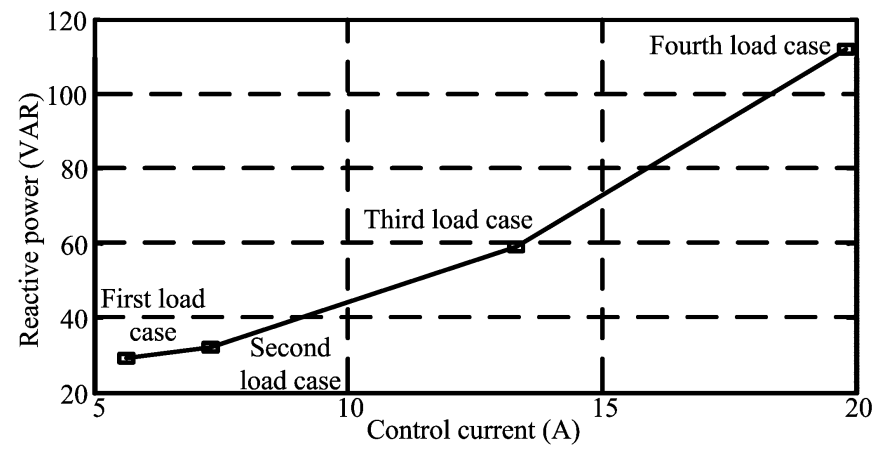

Fig. 16 Measured reactive power consumption for VGR prototype.

\section{Dynamic performance of the VGR}

In order to assess the dynamic performance of the VGR, electrical variables were recorded following load changes. The initial condition is that resulting from the third load case of Table I. At $\mathrm{t}=1.5 \mathrm{~s}$ the capacitive reactance is disconnected and the VGR controller reduces the amount of direct current injected to the control winding; this allows the voltage to remain at $100 \mathrm{Vrms}$ during the period the capacitive reactance is disconnected as seen in Fig. 17a. At the same time, the current consumed by the VGR is less than in the initial condition (Fig. 17c). Then, the capacitive reactance is reconnected at $\mathrm{t}=3.6 \mathrm{~s}$ and the VGR controller increases the direct current injected to the control winding to around $14 \mathrm{~A}$ to reduce the inductance of the VGR and control the voltage (Fig. 17b). This, in turn, decreases the inductance of the VGR and compensates the effects of the capacitive reactance resulting in an unchanged voltage of $100 \mathrm{Vrms}$. Fig. 17 shows that the response time of the controller is within the specified limit.
Finally, the system response to a sudden load rejection event was measured. The second load case from table I was considered as the initial condition.
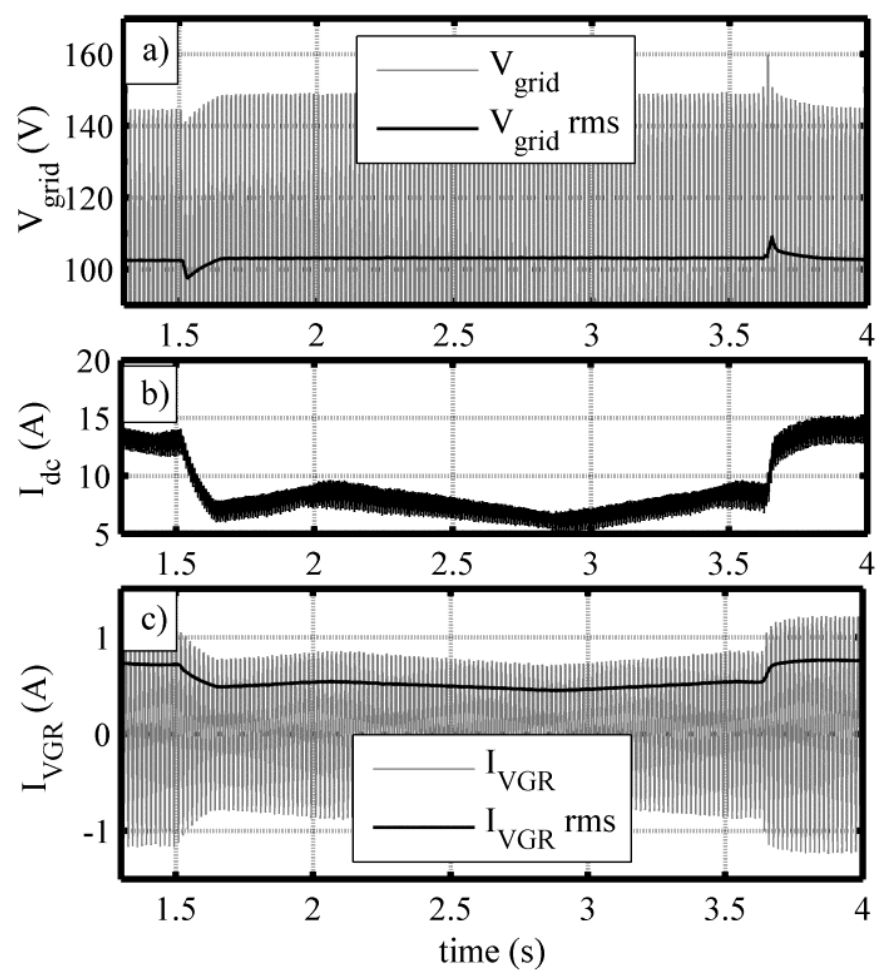

Fig. 17. Experimental dynamic performance with control system. a) Nodal voltage. b) Current in the control winding. c) Current in the main winding.

After a period of time, the resistive-inductive load is suddenly disconnected from the circuit, leaving the shunt capacitive reactance of the line as the only element connected at the load side of the circuit. The load is then connected again, and the sequence repeated several times. Fig. 18 shows how the voltage controller remains stable and acts quickly to increase the direct current injected to the control winding (Fig. $18 \mathrm{~b}$ ) in order to keep the voltage at the pre-established level, as seen in Fig. 18a. The controller keeps a constant voltage despite the severity of the test. Fig. 18c shows the evolution of the current consumed by the VGR during the complete event; this is a consequence of the inductance variation caused by the action of the control system.

In our implementation, the harmonics in the ac current have not been considered. They appear because of the local magnetic saturation in the virtual air gaps. If necessary, they can be limited by modulation of the control current [34]. Inductive filtering is another technique that could be explored in this regard [35], [36].

\section{CONCLUSIONS}

A novel shunt compensation scheme based on a virtual air gap variable reactor (VGR), driven by a digital cascade control, has been successfully demonstrated. The virtual air gap principle was used as the basis for the design of a high voltage variable reactor, and the expected performance was calculated with magnetic field computations. 
To verify the performance of the device and its proposed control, a scaled-down prototype was built and tested. The proposed control, implemented in a digital signal processor, allows a precise and flexible load compensation scheme under different load scenarios tested in the laboratory. The use of the two-degrees-of-freedom IMC controller provides a good dc set point tracking thanks to the use of the internal model concept, an improved secondary winding disturbance rejection and a smooth ac voltage control within the required response time.

Since the VGR is constructed as an electromagnetic system, it is reasonably tolerant to overvoltages and overcurrents. The experimental results show the suitability and flexibility of the proposed control and reactive power compensation scheme, which indicates this new solution is a promising alternative to established reactive power compensation devices, fulfilling the operation requirements of variable reactors such as response time, range of regulation, and regulation smoothness.

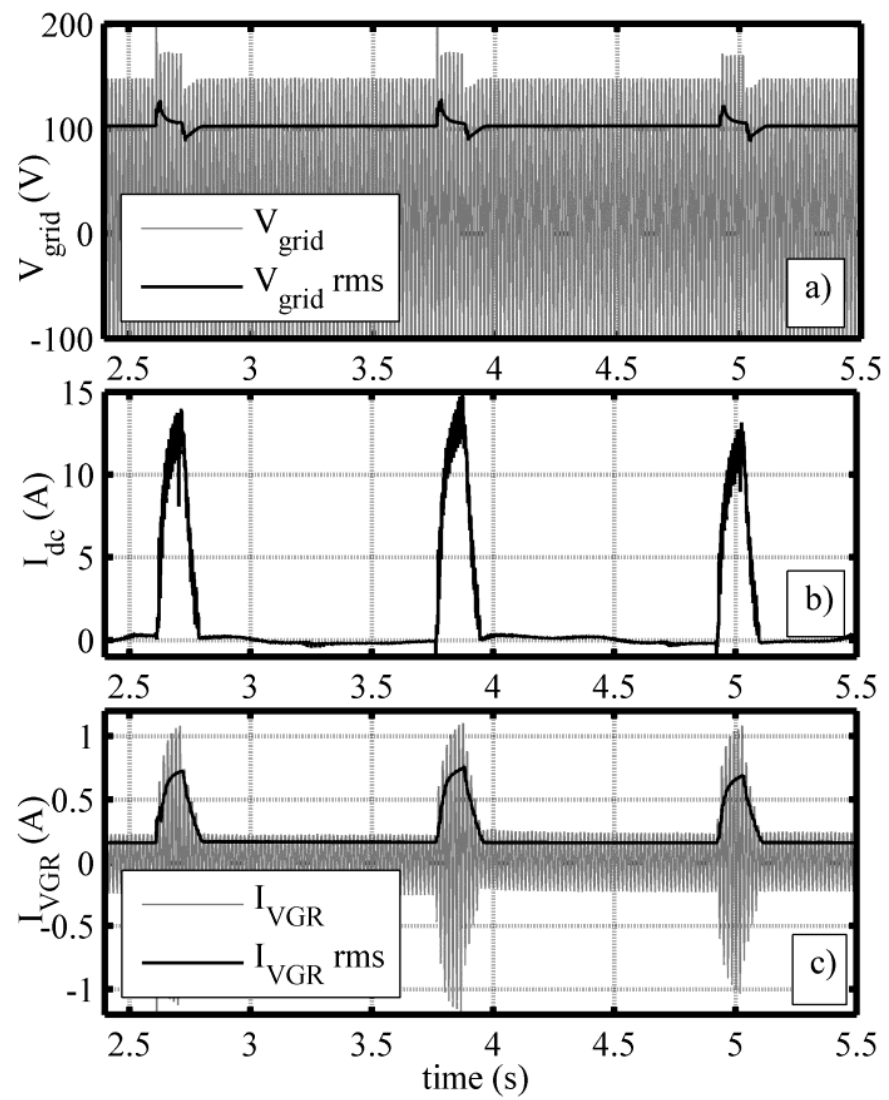

Fig. 18. Experimental dynamic performance during load rejection event with VGR controller enabled. a) Nodal voltage. b) Current in the control winding. c) Current in the main winding.

\section{APPENDIX}

$V G R$ control winding parameters:

$R=0.6 \Omega, L=6.8 \times 10-3 \mathrm{H}$

Controller parameters:

$K_{p}=0.055, \alpha=73.3 \mathrm{rad}, K_{p_{-} v g r}=0.4984$,

$K_{i_{-} v g r}=36.5357, G_{v g r}=-0.1016$

\section{REFERENCES}

[1] P. Kundur, Power System Stability and Control. New York: McGrawHill, 1994, p. 228

[2] G. N. Alexandrov and M. M. Dardeer, "Long distance transmission line with controlled shunt reactors," in Proc. $12^{\text {th }}$ International Middle East Power System Conference, MEPCON, Aswan, March 2008, pp. 294299.

[3] R. Hooper, B. Guy and R. Perrault, "A current controlled variable inductor," in Proc. The System Readiness Technology Conference, AUTOTESTCON, Orlando, September 2010, pp. 1-4.

[4] S. Rahmani, A. Hamadi, K. Al-Haddad and L. A. Dessaint, "A combination of shunt hybrid power filter and thyristor-controlled reactor for power quality," IEEE Trans. Ind. Electron., vol 61, pp. 2152-2164. May. 2014

[5] G. Andersson, R. Levi and E. Osmanbasic, "Dynamic tap-changer testing, reactors and reactance," in Proc. $22^{\text {th }}$ International Conference and Exhibition on Electricity Distribution, CIRED, Stockholm, Jun 2013, pp. 1-4.

[6] Y. Shuji, "Core gap variable reactor", Japan Patent 2008137365, May 27, 2008.

[7] C. Xuxuan, C. Baichao, T. Cuihua, Y. Jiaxin, and L. Yaozhong, "Modelling and harmonic optimization of a two-stage saturable magnetically controlled reactor for an arc suppression coil," IEEE Trans. Ind. Electron., vol. 59, pp. 2824-2831, Jul. 2012.

[8] W. Lee and T. Kim, "Control of the thyristor-controlled reactor for reactive power compensation and load balancing," in Proc. $2^{\text {nd }}$ IEEE Conference on Industrial Electronics and Applications, ICIEA, Harbin, May 2007, pp. 201-206.

[9] H. M. Khattab, S. F. Mekhamer and A. M. A. Mahmoud "Thyristor controlled reactors for reactive power compensation in radial distribution feeders: a developed approach," ICEEC Electrical, Electronic and Computer Engineering., Sept 2004, pp. 852-857.

[10] J. Chen, Y. Li, P. Wang, Z. Yin and Z. Dong, "A novel combined system using cascaded active power filter and static var compensator for high-power applications" in Proc. IEEE conference on Computer Distributed Control and Intelligent Environmental Monitoring, CDCIEM, Changsha, Feb 2011, pp. 664-665.

[11] G. Sheng-jie, R. En-en and T. Ming-xing, "Study on arrangement of harmonic-suppressed winding of controllable reactor of transformer type," In Proc. Power and Energy Engineering Conference, APPEEC, Wuhan, Mar 2011, pp. 1-4.

[12] X. Yang and C. Yue "Orthogonal flux controllable reactor for transmission lines," in Proc. International Conference on Power System Technology, POWERCON, Hangzhou, Oct 2010, pp. 1-4.

[13] Z. Wei-jie and Z. Xiao-xin, "A novel design of flexible controlled shunt reactor," in Proc. International Conference on Power System Technology, POWERCON, Hangzhou, Oct 2010, pp. 1-6.

[14] Y. Youxin and X. Yiping, "Research on one kind of variable reactor," in Proc. International Workshop on Intelligent Systems and Applications, ISA, Wuhan, May 2009, pp. 1-4.

[15] D. Li and J. Tian, "A novel variable reactor with transformer and inverter control," in Proc. $18^{\text {th }}$ International Conference on Electrical Machines, ICEM, Vilamoura, Oct. 2008, pp. 4440-4443.

[16] H. Davaland, S. W. Su and Q. P. Ha, "Design of a variable reactor for load balancing and harmonics elimination," Australasian Universities Power Engineering Conference, AUPEC, Sidney, Dec 2008, pp. 1-6.

[17] J. Ávila, "Electric reactor of controlled reactive power and method to adjust the reactive power," US Patent 7,642,888 B2, Jan. 05, 2010.

[18] V. Molcrette, J. L. Kotny, J. P. Swan and J. P Brudny, "Reduction of inrush current in single phase transformer using virtual air gap technique," IEEE Trans. Magn., vol.34, pp. 1192-1194, Jul. 1998.

[19] A. Konrad and J.F. Budny, "An improved method for virtual air gap length computation," IEEE Trans. Magn., vol.41, pp. 4051-4053, Oct. 2005.

[20] S. Magdaleno and C. P. Rojas, "Control of magnetizing characteristics of a toroidal core using virtual gap," in Proc. Electronics, Robotics and Automotive Mechanics Conference, CERMA, Cuernavaca, Sep. 2010, pp. 540-545.

[21] J. Avila-Montes, E. Melgoza, "Scaling the virtual air gap principle to high voltage large power applications," in Proc. XXth International 
Conference on Electrical Machines, ICEM, Marseille, Sep. 2012, pp. 757-762.

[22] O. Ocak, B. T. Ertugrul, E. Sincar, C. Oysu and M. Aydin, "Design, analysis and experimental verification of a permanent magnet ac servomotor for mobile robot applications," in Proc. XXth International Conference on Electrical Machines, ICEM, Marseille, Sep. 2012, pp. 196-200.

[23] P. Handgruber, A. Stermeckci, O. Bíró, A. Belahcen and E. Dlala, “3-D eddy current analysis in steel laminations of electrical machines as a contribution for improved iron loss modeling," in Proc. XXth International Conference on Electrical Machines, ICEM, Marseille, Sep. 2012, pp. 16-22.

[24] A. M. Mihai, S. Benelghai, A. Simion, R. Outbib and L. Livadrau, "Design and FEM analysis of five-phase permanent magnet generators for gearless small-scale wind turbines," in Proc. XXth International Conference on Electrical Machines, ICEM, Marseille, Sep. 2012, pp. 150-156.

[25] B. Tomičić, S. Car and Ž. Štih, "An improved model of synchronous generator based on finite element method analysis," in Proc. XXth International Conference on Electrical Machines, ICEM, Marseille, Sep. 2012, pp. 47-52.

[26] D. S. L. Dolan, "Analysis of a virtual air gap variable reactor," in Proc. IEEE Power Electronics Specialists Conference, Orlando, Jun. 2007, pp. 1182-1187.

[27] Melgoza, E.; Avila-Montes, J.; Madrigal, Manuel, "Analysis of the magnetic characteristics of virtual-gap reactors, "IEEE International Autumn Meeting on Power, Electronics and Computing (ROPEC), 2013, pp.1,6, 13-15 Nov. 2013

[28] D. Campos-Gaona, E. L. Moreno-Goytia and O. Anaya-Lara, "Fault ride-through improvement of DFIG-WT by integrating a two-degreesof-freedom internal model control," IEEE Trans. Ind. Electron., vol. 60, pp.1133-1145, Mar. 2013.

[29] L. Harnefors and H. P. Nee, "Model-based current control of ac machines using the internal model control method," IEEE Trans. Ind. Appl., vol.34, pp. 133-141, Jan./Feb. 1998.

[30] I. Kaya, "Two-degree-of-freedom IMC structure and controller design for integrating processes based on gain and phase-margin specifications," IEE Proc. Control Theory Appl., vol. 151, pp. 481- 487, Jul. 2004.

[31] X. Changliang, Y. Yan, P. Song and T. Shi, "Voltage disturbance rejection for matrix converter-based PMSM drive system using internal model control," IEEE Trans. Ind. Electron., vol. 59, pp. 361-372, Jan. 2012.

[32] H. Sepahvand, L. Jingsheng and M. Ferdowsi, "Investigation on capacitor voltage regulation in cascaded H-bridge multilevel converters with fundamental frequency switching," IEEE Trans. Ind. Electron., vol. 58, pp. 5102-5111, Nov. 2011.

[33] E. Villanueva, P. Correa, J. Rodriguez, and M. Pacas, "Control of a single-phase cascaded H-bridge multilevel inverter for grid-connected photovoltaic systems," IEEE Trans. Ind. Electron., vol. 56, pp. 43994406, Nov. 2009.

[34] Dolan, D.S.L.; Lehn, P.W., "Harmonics and Dynamic Response of a Virtual Air Gap Variable Reactor," Ninth International Conference on Information Technology: New Generations (ITNG), 2012, pp.225,231, 16-18 April 2012

[35] Y. Li, L. Luo, C. Rehtanz, C. Wang and S. Rüberg, "Simulation of the electromagnetic response characteristic of an inductively filtered HVDC converter transformer using field-circuit coupling," IEEE Trans. Ind. Electron., vol. 59, pp. 4020-4031, Nov. 2012.

[36] Y. Li, L. Luo, C. Rehtanz, S. Rüberg, D. Yang and J. Xu, "An industrial dc power supply system based on an inductive filtering method," IEEE Trans. Ind. Electron., vol. 59, pp. 714-722, Feb. 2012.

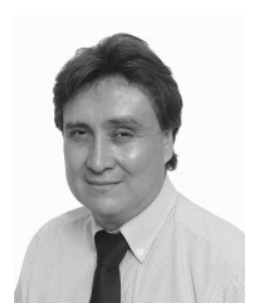

J. Avila-Montes (S'07) was born in México in 1969. He received the B.S in electrical engineering from Instituto Tecnológico de Morelia (ITM), Michoacán, México, and M.S degree from Universidad Autónoma de Nuevo Leon in 1995. Since 1995 he has been with Prolec GE, as a design up to 2005. Currently he is leader of technology projects in the applied research center of Prolec GE. His interests include electric power transformers and EHV shunt reactors design, voltage stability analysis and load compensation schemes design in power systems.

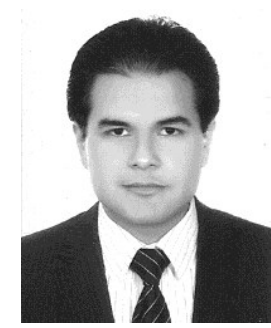

David Campos-Gaona. (M'12) He received the B.E. in Electronic engineering and M.Sc. in Electrical engineering degrees from Instituto Tecnológico de Morelia, Morelia, Mexico, in 2004 and 2007 respectively. He completed his Ph.D. degree in 2012 in the same institution. His research area interest includes wind farm power integration and HVDC transmission system and control of power electronic devices.

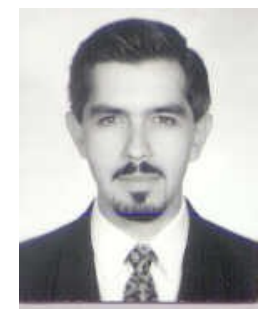

Enrique Melgoza Vázquez (S'93-M'96-SM'10) was born in1967 in Morelia, México. He received the B.Sc. and M.Sc. degrees in Electrical Engineering from Instituto Tecnológico de Morelia (ITM) in 1994 and 1996, respectively, and a $\mathrm{Ph}$. D. degree from the University of Bath, UK, in 2001. He is member of the faculty at ITM's Programa de Graduados e Investigación en Ingeniería Eléctrica. His professional experience includes several positions as a distribution engineer, and consulting and training for several electricity-related companies, in Mexico and abroad. He is a senior member of the Institute of Electrical and Electronics Engineers. His interests include finite element analysis of electromagnetic fields and electromagnetic transients.

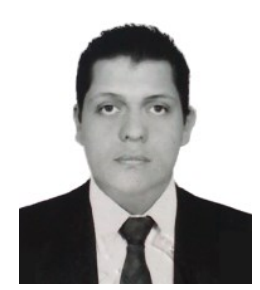

J.R. Rodríguez Rodríguez (S’09) Received the B.E. in Electronics Engineering from Instituto Tecnológico de Morelia, Michoacán, México in 2010. He specialized in digital design in the PADTS10 at Guadalajara campus of CINVESTAV in Mexico in 2011 . He is currently working towards his $\mathrm{Ph} . \mathrm{D}$. degree in electrical power systems at the Instituto Tecnológico de Morelia. His areas of interest are: Power Electronics Converters and Power 